\title{
Evaluation of Gas Diffusion Coefficients in Membrane by the Volumetric Permeability Apparatus of the Piston-Feeder Type
}

\author{
Teruhiko Baba, Masaji Matsuda, Kenji Haraya, \\ Chiyoshi Kamizawa and Woo-Tai Lee*
}

National Chemical Laboratory for Industry, Tsukuba, Ibaraki 305 (Japan)

*Department of Chemical Engineering, Chonnam National University. Kwangju 500 (Korea)

\section{ピストンを用いた容積型透過性測定装置による膜内気体拡散係数の評価}

\author{
馬場照彦・松田正治・原谷賢治・神沢千代志・李 愚台* \\ 化学技術研究所 齿305 茨城県つくば市東 $1-1$ \\ *全南大学校工科大学化学工学科 焉500 大韓民国光州直轄市
}

\begin{abstract}
The applicability of the newly developed permeability apparatus of the piston-feeder type to the evaluation of the gas diffusion coefficients in membrane were examined using silicone rubber $/ \mathrm{O}_{2}$ and / $\mathrm{N}_{2}$ systems at $15^{\circ} \mathrm{C}$. The data for the gas diffusivity were obtained by the time lag method and these values were in good agreement with those obtained by the apparatus of the high-vacuum type. Such results were demonstrated for the first time in the case of the volumetric method and suggest that the newly developed permeability apparatus is sufficiently applicable to the evaluations of the diffusivity as well as the permeability, if only the pre-experimental conditions can be set up properly. Meanwhile, it was also actually observed that time lag is much affected with the initial deviation of the gas distribution between the inside and the outside of membrane. This phenomenon is always liable to occur in the case of the volumetric method and the experimental results could be well-described by the Fickian desorption mechanism in the case that the gas concentration in membrane is higher than the equilibrium concentration defined by the outside pressure. From this consideration, the criteria of the initial set-up conditions for the valid evaluations in the repeated measurements were discussed.
\end{abstract}

Key words : Volumetric method, Diffusion coefficient, Permeability, Time lag, Deviation of gas distribution, Fickian desorption

\section{Introduction}

The gas permeation parameters of polymer membranes are the important characteristics to evaluate the barrier property of the packaging materials, e.g. for foods or medicines, and the performance of the gas separation membranes" ${ }^{1}$, e.g. for oxygen enrichment. Therefore, it is desirable to employ the convenient permeability apparatus capable of the accurate measurement. Among the various methods for permeation measurement, the manometric method, especially, the high-vacuum technique is most useful to obtain 
the accurate parameters, that is, for permeability, solubility and diffusivity ${ }^{2)}$. For the simpler and routine measurements, the low-vacuum technique or the volumetric method are more suitable but not so much accurate and the former taken as inadequate to estimate the diffusivity ${ }^{2)}$. Meanwhile, concerning the estimation of the diffusivity by the use of the conventional volumetric permeability apparatus, very few studies ${ }^{3)}$ have mentioned, although many permeability data have been obtained. It is probably attributed to the experimental difficulty.

As previously reported ${ }^{4)}$, we have developed the new-type permeability apparatus, which is based on the volumetric method and the gas pressure differences across the membrane can be controlled with piston in the gas feed side. This apparatus could be readily operated and supply the permeability data in a very good precision and reproducibility.

In the present study, we examined the applicability of the above apparatus to the evaluation of the gas diffusion coefficients, using a silicone rubber membrane as a model membrane. Moreover, we considered the effects of the initial deviation of the gas distribution between the inside and outside of membrane on the subject measurements and provided the initial set-up conditions for the valid evaluations.

\section{Theoretical Background}

If the gas permeation through polymer membranes obeys onedimensional Fickian diffusion, the gas flux density, $J$, is expressed :

$$
J=-D(d C / d x)
$$

where $D, C$ and $x$ are the diffusion coefficient, the gas concentration and the position in membrane, $0 \leqq x \leqq L$, respectively ${ }^{5)}$. $L$ is the membrane thickness. Meanwhile, when the polymer membrane is at the rubber state, $C$ is expressed :

$$
C=S p
$$

where $S$ is the solubility coefficient and $p$ is the equilibrium pressure. Therefore, eqn. (1) can be rewritten as follows :

$$
J=-D S(d p / d x)=-P(d p / d x)
$$

where $P$ is the permeability coefficient ${ }^{5)}$.

The method for the evaluation of $D$ has been first shown by Daynes ${ }^{6)}$ as "time lag method," which is based on the general solution of Fickian diffusion equation for the following boundary conditions :

$$
\begin{aligned}
& C=C_{1}(x=0, t \geqq 0) \\
& C=C_{2}(x=L, t \geqq 0) \\
& C=f(x) \quad(0<x<L, t=0)
\end{aligned}
$$

where 1 and 2 refer to the feed side and the permeation side, respectively. According to Daynes ${ }^{6}$, the expression for the concentration in this case is :

$$
\begin{aligned}
& C=C_{1}+\left(C_{2}-C_{1}\right)\left(\frac{x}{L}\right)+\frac{2}{\pi} \sum_{n=1}^{\infty} \frac{C_{2} \cos n \pi-C_{1}}{n} \\
& \times \sin \left(\frac{n \pi x}{L}\right) \exp \left(-\frac{D n^{2} \pi^{2} t}{L^{2}}\right)+\frac{2}{L} \sum_{n=1}^{\infty} \sin \left(\frac{n \pi x}{L}\right) \\
& \times \exp \left(-\frac{D n^{2} \pi^{2} t}{L^{2}}\right) \times \int_{0}^{L} f\left(x^{\prime}\right) \sin \left(\frac{n \pi x}{L}\right) d x^{\prime}
\end{aligned}
$$

If the distribution of gas concentration in membrane, $f(x)$, is constant, $C_{3}$, the integral amount of permeation, $Q$, can be expressed from eqn. (1) and (5) as follows :

$$
\begin{aligned}
Q & =A \int_{0}^{t} J(x=L) d t=\frac{A D\left(C_{1}-C_{2}\right)}{L} \\
& \times\left[t-\frac{L^{2}}{6 D} \cdot \frac{C_{1}+2 C_{2}-3 C_{3}}{C_{1}-C_{2}} \times\right. \\
& \left.\left\{1+\frac{12}{\pi^{2}} \times \sum_{n=1}^{\infty} \frac{(-1)^{2}}{n^{2}} \exp \left(-\frac{D n^{2} \pi^{2} t}{L^{2}}\right)\right\}\right]
\end{aligned}
$$

where $A$ is the membrane area. As $t \rightarrow \infty$, eqn. (6) asymptotically approaches the line :

$$
Q=\frac{A D\left(C_{1}-C_{2}\right)}{L}\left(t-\frac{L^{2}}{6 D} \cdot \frac{C_{1}+2 C_{2}-3 C_{3}}{C_{1}-C_{2}}\right)
$$

The intercept of this line on $t$ axis is the time lag, $\theta$, and related to $D$ as follows ${ }^{7,8)}$ :

$$
\theta=\frac{L^{2}}{6 D} \cdot \frac{C_{1}+2 C_{2}-3 C_{3}}{C_{1}-C_{2}}
$$

Here, we rewrote eqn. (8) with equilibrium pressure by using eqn. (2) as follows :

$$
\theta=\frac{L^{2}}{6 D}\left\{1+(1-k)\left(\frac{3 r}{1-r}\right)\right\}
$$

where $r$ is the pressure ratio, $\left(p_{2} / p_{1}\right)$, and $k$ is the 


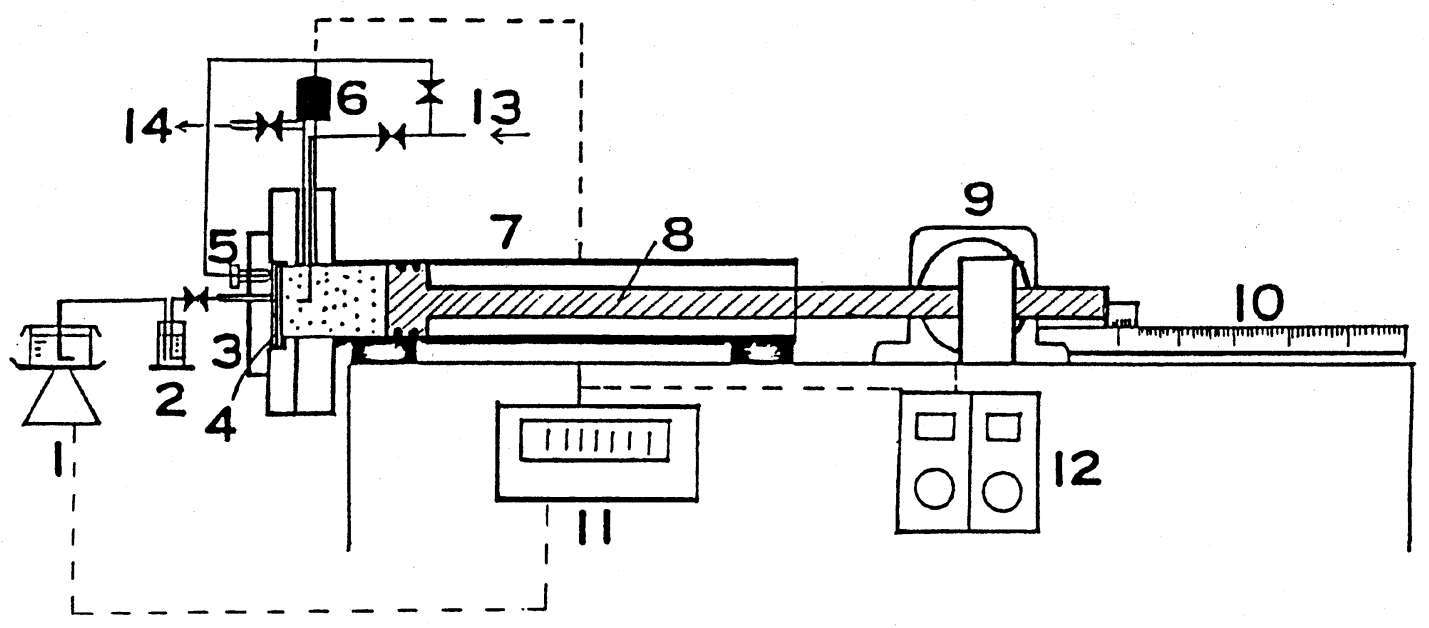

Fig. 1 Schematic diagram of the volumetric apparatus of the piston-feeder type

1. balance; 2. water sealed tube ; 3 . permeability cell ; 4. membrane ; 5 . needle valve; 6 . pressure difference sensor ; 7. cylinder ; 8. piston ; 9. motor ; 10. scale ; 11. recorder ; 12. controller; 13. gas inlet; 14. gas outlet.

parameter for the initial deviation of the gas distribution between the inside and outside of membrane, $\left(p_{3} / p_{2}\right) . p_{3}$ is the hypothetical equilibrium pressure corresponding to $C_{3}$. The case of $k=1$ is defined as the equilibrium state for the gas distribution except $p_{2}=0$. The second term containing $k$ in eqn. (9) should be named "non-equilibrium term".

In the case of $k=1$, eqn. (9) becomes eqn. (10) :

$$
\theta=\frac{L^{2}}{6 D}
$$

and $D$ can be calculated immediately from $L$ and $\theta$. To the evaluations of $D$ by the conventional manometric method, eqn. (10) is always applicable since the initial pressures, $p_{2}$ and $p_{3}$ are experimentally $0^{6,7,9)}$. However, in the case of the volumetric apparatus, $p_{2}$ is atmospheric pressure and $p_{3}$ is not always equlibrated with $p_{2}$. Therefore, it is necessary to consider the non-equilibrium term indicated by eqn. (9).

\section{Experimental}

Silicone rubber membranes used were $2.1 \mathrm{~mm}$ thick and supplied by the Shin-Etsu Chemical Co., Ltd. The gases used were $\mathrm{O}_{2}$ and $\mathrm{N}_{2}$, supplied by the Nihon Sanso Co., Ltd., at least $99.9 \%$ pure. The detail of the volumetric permeability apparatus, of which the schematic diagram is shown in Fig. 1, was described elsewhere ${ }^{4)}$. The permeability apparatus based on the high-vacuum technique was also employed. The effective areas of membranes were $12.6 \mathrm{~cm}^{2}$ in the case of the volumetric apparatus and $8.2 \mathrm{~cm}^{2}$ in the case of the high-vacuum apparatus.

The permeation experiments under the ordinary conditions $(k=1)$ were carried out by the following procedure. Referring to Fig. 1, the sample gas was introduced into the cylinder (7) of the feed side to remove the remaining air in the cylinder, after the membrane (4) was attached to the cell (3). In the similar manner, the air in the tube lines of the permeation side was also substituted with the sample gas and set to the atmospheric pressure $(1 \mathrm{~atm})$. The removal of the remaining air in the membrane was carried out by the permeation of the sample gas for several hours. Subsequently, the pressure difference between the feed and the permeation sides, $p_{1}-p_{2}$, was set to 0 and stood for several hours in order to preequilibrate the inside with the outside of the mem- 


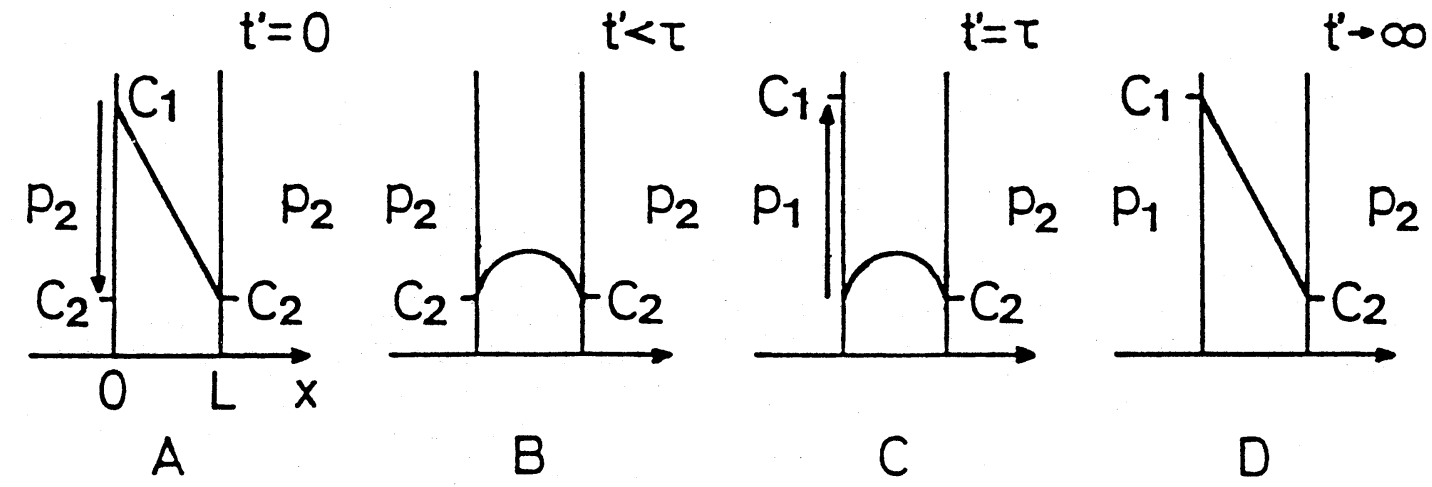

Fig. 2 Procedure of the permeation experiment under the special condition; see Experimental.

brane. The permeation measurements were started at $t=0$, when the feed pressure went up to the desired pressure, and the integral amount of permeation was recorded automatically as an integral weight of the substituted water in the water sealed tube (2) by the permeating gas. The time loss required to go up to the desired feed pressure from $1 \mathrm{~atm}$ on the feed side was within $10 \mathrm{sec}$. The measurements were performed at $15^{\circ} \mathrm{C}\left( \pm 1^{\circ} \mathrm{C}\right)$ and ranging in pressure difference from 0.5 to 3.0 atm.

In the case of the high-vacuum apparatus, the integral amount of permeation was monitored at $p_{1}=1$ atm as a pressure change of the permeation side by the use of an MKS Baratron pressure transducer after the apparatus was evacuated under $10^{-4} \mathrm{mmHg}$. Temperature were accurate within $0.2^{\circ} \mathrm{C}$.

On the other hand, the effects of the initial deviation of the gas distribution between the inside and the outside of membrane $(k \neq 1)$ on the evaluation of the diffusion coefficients were examined by the following procedure. As shown in Fig. 2, the pressure difference of the permeating system at steady-state is set to 0 at $t^{\prime}=0(\mathrm{~A})$, and then the gas distribution will change with time to come to equilibrium (B). But at a finite standing time $t^{\prime}=$ $\tau$, the gas distribution will still remain at nonequilibrium state (C). At this state, the feed pressure is set to the original pressure again and the permeation measurements are newly performed
(D). The effects of these conditions $(k>1)$ will reflect the relationships between the standing time, $\tau$, and the time lag, $\theta$. The total time loss required to set to 1 atm from the initial feed pressure and set to the original feed pressure from 1 atm again was within $15 \mathrm{sec}$.

Moreover, the effects of the temperature changes accompanied by the above operations of gas compression and expansion could not be observed at all.

\section{Results and discussion}

Silicone rubber $/ \mathrm{O}_{2}$ or $/ \mathrm{N}_{2}$ systems were selected from the standpoint of their usefulness and advantage, not only the practical use, e.g. the permselective membranes for oxygen enrichment, but the suitability to check the performance of the permeability apparatus, because ; 1) the permeation occurs by a simple solution-diffusion mechanism, that is, permeabilities of these gases are independent of the pressure differences ; 2) the solubilities of these gases are low enough not to alter the property of membrane and 3) permeability is much high.

\section{Evaluation of the gas diffusion coefficients}

Fig. 3 shows the integral permeation curves for $\mathrm{O}_{2}$ at various pressure differences, $p_{1}-p_{2}$. It has been reported that the permeability coefficients of silicone rubber to $\mathrm{O}_{2}$ and $\mathrm{N}_{2}$ are independent of 


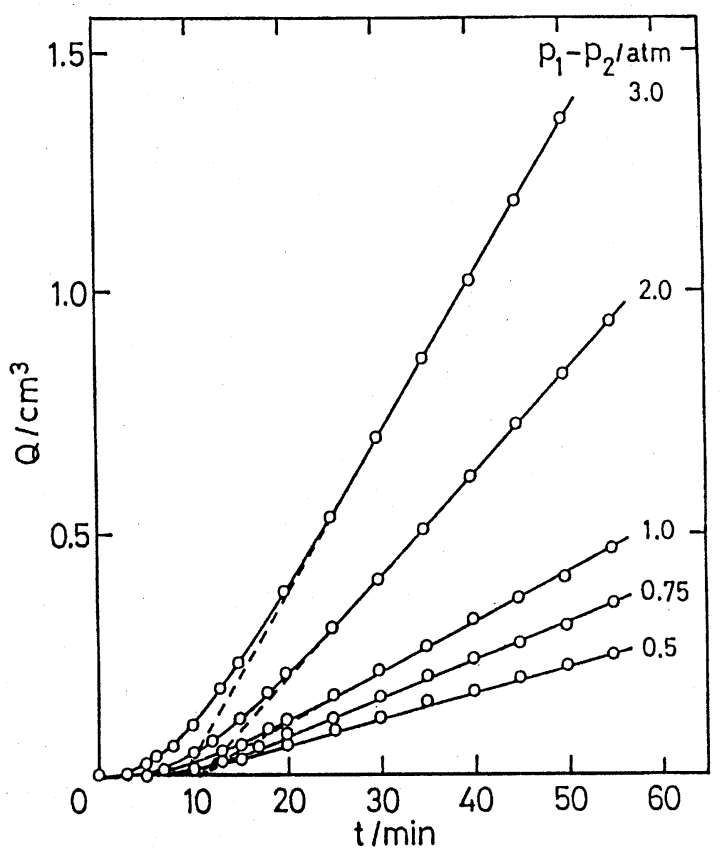

Fig. 3 Integral permeation curves for $\mathrm{O}_{2}$ at various pressure differences and at $15^{\circ} \mathrm{C}$.

pressure difference ${ }^{10)}$. Our results are also similar to the author's and $P_{o}=3.74 \pm 0.10 \times 10^{-8} \mathrm{~cm}^{3}$ $(\mathrm{STP}) \cdot \mathrm{cm} \cdot \mathrm{s}^{-1} \cdot \mathrm{cm}^{-2} \cdot \mathrm{cmHg}^{-1}$ at $15^{\circ} \mathrm{C}$, calculated from the slopes of the linear region of the curves. Meanwhile, the non-steady-state flow region was observed and the extrapolated values of the linear region to $t$ axis, that is, time lag were almost constant, independent of pressure difference. Although the time lag has been scarcely referred to in the case of the conventional volumetric method, these results support the applicability of the time lag method to the evaluation of the gas diffusion coefficients when the pre-experimental conditions can be set up properly.

According to eqn.(9), $D$ can be calculated from the time lag, $\theta$. But if $k$ is not $1, \theta$ will be obtained as a function of $3 r /(1-r)$. Fig. 4 shows the relationships between $\theta$ and $3 r /(1-r)$ or $p_{1}-p_{2}$ for $\mathrm{O}_{2}$ and $\mathrm{N}_{2}$ under the ordinary condition, and $\theta$ for both gases are independent of $3 r /(1-r)$ or $p_{1}-p_{2}$, indicating the equilibrium of the gas distribution

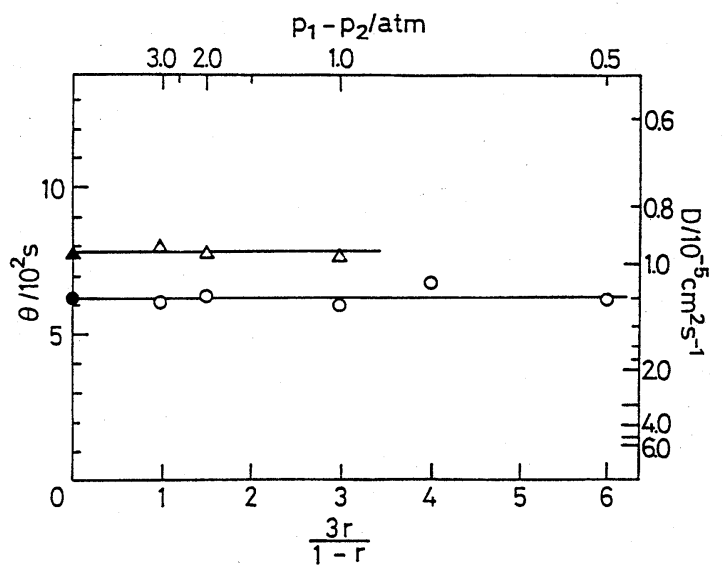

Fig. 4 Relationships between time lag and 3 $r /(1-r)$ or pressure difference at $15^{\circ} \mathrm{C}$ : (○) $\mathrm{O}_{2} ;(\Delta \boldsymbol{\Delta}) \mathrm{N}_{2}$. Closed symbols: data obtained by the use of the high vacuum apparatus.

is established $(k=1)$. Therefore, $D$ can be calculated in terms of eqn. (10) and $D_{o}=1.20 \pm 0.10 \times$ $10^{-5} \mathrm{~cm}^{2} \cdot \mathrm{s}^{-1}, D_{N}=9.43 \pm 0.20 \times 10^{-6} \mathrm{~cm}^{2} \cdot \mathrm{s}^{-1}$. On the other hand, the results obtained by the highvacuum apparatus are also shown in Fig. 4 and these values are in good agreement with the above mentioned ones. This fact suggests that the time lag method is much valid even for the use of the volumetric apparatus and can provide the proper values for the gas diffusivity.

Fig. 5 shows the temperature dependence of the diffusion coefficients for $\mathrm{O}_{2}$ and $\mathrm{N}_{2}$ obtained by the high-vacuum apparatus and the volumetric one (at $15^{\circ} \mathrm{C}$ ), together with the results obtained by the other authors ${ }^{11,12)}$. Although the pre-exponential factors of three independent experiments are more or less different from eacr other, the apparent activation energies for diffusion are almost similar. This observation suggests that the highvacuum apparatus used in the present study was also sufficiently reliable.

\section{Effects of the initial deviation of the gas distribution on the measurements}

When the gas disribution between the inside and 


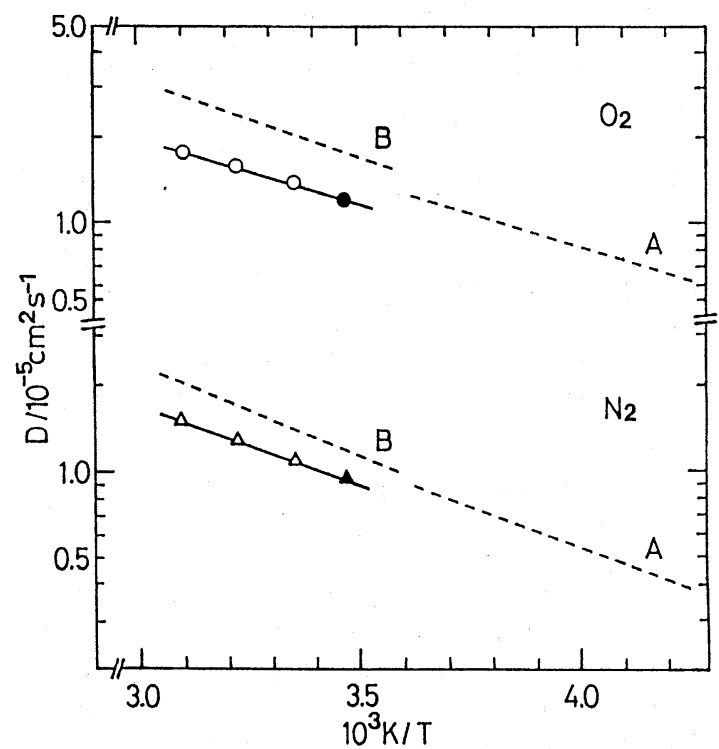

Fig. 5 Temperature dependence of the diffusion coefficients : $(\bigcirc \bigcirc) \mathrm{O}_{2} ;(\triangle \mathbf{\Delta}) \mathrm{N}_{2}$. Closed symbols : data obtained by the use of the volumetric apparatus. Broken lines represent data of : (A) Barrer et al. ${ }^{11)} ;(\mathrm{B})$ Minoura et al. ${ }^{12)}$

the outside of membrane deviates from the equilibrium state ; e.g. when the air or other gas contaminant exists in the membrane due to the incomplete removal by the sample gas; when the gas concentration in the membrane is in disagreement with the equilibrium concentration defined by the outside pressure, the diffusion coefficients can not be simply calculated from the time lag. This problem occurs only in the case of the volumetric method, so long as both the feed and the permeation sides of the apparatus are initially set to a finite pressure, and is liable to give the unreliable data for the diffusivity.

For the high-vacuum method, it is easy to set to a definite initial condition, if only the system of the apparatus, e.g. tube lines, diffusion cell and membrane are collectively evacuated until a definite pressure is reached, and the time required to reach a definite pressure can be easily estimated by use of a manometer. But for the volumetric method, it is practically difficult to predict the

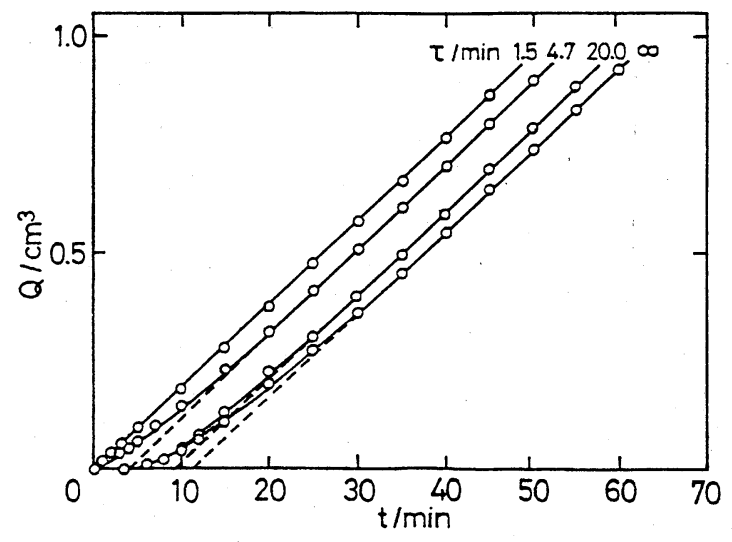

Fig. 6 Effect of the standing time on the integral permeation curves for $\mathrm{N}_{2}$ at $15^{\circ} \mathrm{C}$.

time required to reach the equilibrium of the gas distribution between the inside and the outside of membrane. When this system is left for a very long period, the equilibrium is of course reached. But it is much inconvenient for the repeated measurements. Therefore, it is necessary to obtain the time measure for the initial set-up condition.

In what follows, the effects of the initial deviation of the gas distribution on the measurements will be considered quantitatively, limited to the case that gas concentration in membrane is higher than the equilibrium concentration defined by the outside pressure, that is, $k>1$.

Fig. 6 shows the integral permeation curves for $\mathrm{N}_{2}$ at various standing times, $\tau$, and pressure difference was set to $3 \mathrm{~atm}$. The slope of the linear region of each curve, that is, $P$ is constant regardless of $\tau$, however, the curve is shifted to the left by shortning of $\tau$. When the membrane is stood for a very long period, time lag, $\theta$, shows its largest value and it agrees with the one obtained under the ordinary condition $(k=1)$. Even in the case of $k>1, D$ should be constant regardless of $\tau$ since both $P$ and $S$ are constant. Therefore, the change of $\theta$ can be interpreted with not the actual change of $D$, but the non-equilibrium term in eqn. (9).

Next the expression of the non-equilibrium term free from $C_{3}$, which can not be measured directly, 


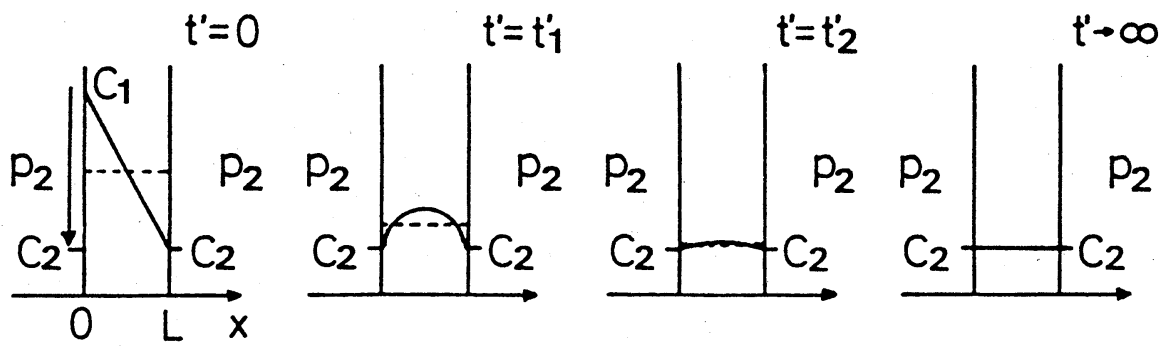

Fig. 7 Process of the gas desorption from membrane after the pressure difference set to 0 . The broken line in membrane represents the average gas concentration $\bar{C}_{3}$.

will be attempted to explain the above observed phenomena. As shown in Fig. 7, the gas concentration in membrane at $t^{\prime}=0$ is relatively higher than those at membrane surfaces, and hence the former concentration will decrease by way of the gas desorption process. During this process, the average gas concentration in membrane, $\bar{C}_{3}$, shown by the broken line in Fig. 7, and/or the average pressure, $\bar{p}_{3}$, will also decay with time until equilibrium is established. If this desorption process can be described by Fickian diffusion equation, we can give the boundary conditions as follows :

$$
\begin{aligned}
& C=C_{2}\left(x=0, t^{\prime} \geqq 0\right) \\
& C=C_{2}\left(x=L, t^{\prime} \geqq 0\right) \\
& C=\left(C_{2}-C_{1}\right)(x / L)+C_{1} \quad\left(0<x<L, t^{\prime}=0\right)
\end{aligned}
$$

and obtain $C_{3}\left(x, t^{\prime}\right)$ from eqn. (5) as eqn. (12) :

$$
\begin{aligned}
C_{3}\left(x, t^{\prime}\right) & =C_{2}+\frac{2\left(C_{1}-C_{2}\right)}{\pi} \sum_{n=1}^{\infty} \frac{1}{n} \\
& \times \sin \left(\frac{n \pi x}{L}\right) \exp \left(-\frac{D n^{2} \pi^{2} t^{\prime}}{L^{2}}\right)
\end{aligned}
$$

Moreover, if $C_{3}\left(x, t^{\prime}\right)$ can be averaged over the position in membrane, $x$, eqn. (12) becomes simpler and only time-dependent :

$$
\begin{aligned}
\bar{C}_{3}\left(t^{\prime}\right) & =\overline{S p}_{3}\left(t^{\prime}\right)=\int_{0}^{L} C_{3}\left(x, t^{\prime}\right) d x / \int_{0}^{L} d x \\
& =C_{2}+\frac{4\left(C_{1}-C_{2}\right)}{\pi^{2}} \sum_{n=1}^{\infty} \frac{1}{(2 n-1)^{2}} \\
& \times \exp \left\{\frac{D(2 n-1)^{2} \pi^{2} t^{\prime}}{L^{2}}\right\}
\end{aligned}
$$

Therefore, the gas distribution in membrane at $t^{\prime}$ $=\tau$ and the average gas concentration in membrane at $t^{\prime}=\tau$ can be obtained by eqn.(12) and
(13), respectively. When eqn. (12) is substituted in eqn. (5) as $f(x)$, the mathematically strict relationship between $\theta$ and $\tau$ can be obtained, but it is much complex. So we assumed that $C_{3}$ and/ or $p_{3}$ in the non-equilibrium term in eqn.(9) could be described by eqn. (13). When eqn. (13) is substituted in eqn.(9), the approximated relationship between $\theta$ and $\tau$ is afforded as follows :

$$
\begin{aligned}
\theta(\tau)= & \frac{L^{2}}{6 D}\left[1-\frac{12}{\pi^{2}} \frac{1}{(2 n-1)^{2}}\right. \\
& \left.\times \exp \left\{-\frac{D(2 n-1)^{2} \pi^{2} \tau}{L^{2}}\right\}\right] \\
= & \theta_{\infty}\left[1-\frac{12}{\pi^{2}} \sum_{n=1}^{\infty} \frac{1}{(2 n-1)^{2}}\right. \\
& \left.\times \exp \left\{-\frac{(2 n-1)^{2} \pi^{2} \tau}{6 \theta_{\infty}}\right\}\right]
\end{aligned}
$$

where $\theta_{\infty}$ is the intrinsic time lag, from which $D$ can be evaluated directly.

Fig. 8 shows the experimental relationship between $\left(\theta / \theta_{\infty}\right)$ and $\left(\tau / \theta_{\infty}\right)$ for $\mathrm{N}_{2}$ at 1 atm and 3 atm of pressure difference. Further, the theoretical approximation curve from eqn.(14) and the calculated $\bar{p}_{3}$ curve from eqn.(13) at 3 atm of pressure difference are also shown by the full line and the broken one, respectively. The theoretical approximation curve describes the experimental data very well, concluding eqn. (14) can approximate the relationship between $\theta$ and $\tau$ sufficiently. Moreover, eqn.(14) is independent of pressure difference and this also agrees with the experimental data. Thus, the assumption that the desorption of gas from a rubber membrane proceeds by Fickian diffusion mechanism, is considered to be substan- 


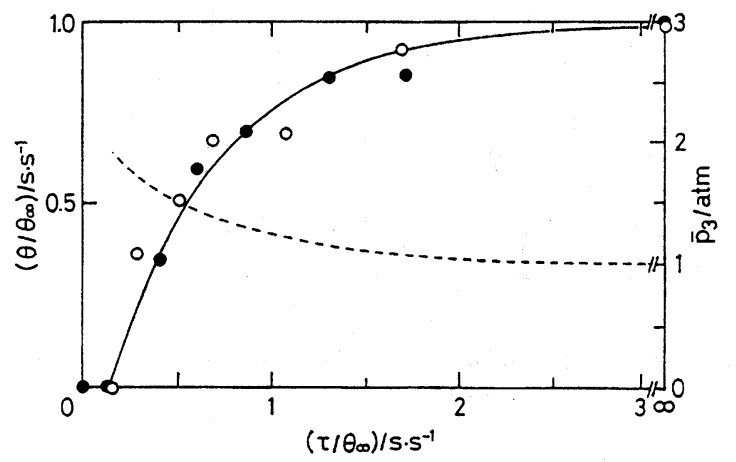

Fig. 8 Relationship between time lag and standing time for $\mathrm{N}_{2}$ at $15^{\circ} \mathrm{C}$ ( $\left.\bigcirc\right) 1$ atm; (O) $3 \mathrm{~atm}$. The full line represents the theoretical approximation curve calculated from eqn. (14) and the broken line represents the calculated decay curve for the hypothetical equilibrium pressure in membrane from eqn. (13) at 3 atm of pressure difference.

tially appropriate. In addition, this consideration also suggests the possibility of the other use of our apparatus in principle: the method for judging whether the desorption of gas from a polymer membrane proceeds by Fickian type or not.

Comparing eqn. (9) with eqn. (14), the parameter, $k$, can be expressed as follows :

$k=1+\frac{4}{\pi^{2}}\left(\frac{1}{r}-1\right) \sum_{n=1}^{\infty} \frac{1}{(2 n-1)^{2}} \exp \left\{-\frac{(2 n-1)^{2} \pi^{2} \tau}{6 \theta_{\infty}}\right\}$

But this equation is unsuitable to describe the state at $\tau$ near 0 . As $\tau \rightarrow \infty, k$ approaches 1 , that is, the system reaches equilibrium, however, the nonequilibrium term become close to 0 after a period of about $2.5 \sim 3$ times the intrinsic time lag. Therefore, in the repeated measurements with the same gas, there is little effect of the initial deviation of the gas distribution on the time lag method, if only the remeasurement will be performed after standing for the above period. For example, as can be seen from Fig. $8, \theta$ is close to its intrinsic value and $p_{3}$ agrees very closely with the atmospheric pressure at $\left(\tau / \theta_{\infty}\right) \sim 3($ ca. $30 \mathrm{~min})$. A similar observation has been shown concerning the integral permeation curve, that is, the steadystate flow is also established after a period of about 3 times the time $\operatorname{lag}^{5)}$. This agreement is of course due to the same basis of their phenomena.

From the above discussion, the effects of the initial deviation of the gas distribution on the measurements could be quantified within the scope of the present experiments.

\section{Conclusions}

In the present study, it was shown that the volumetric permeability apparatus of the piston-feeder type is much applicable to the evaluation of the gas diffusion coefficients as well as the gas permeability coefficients in the case of a rubber membrane. The results were obtained by the time lag method in a good precision and without any complicated operations. Moreover, it was actually observed that time lag is much affected with the initial deviation of the gas distribution between the inside and the outside of membrane. This phenomenon is always liable to occur in the case of the volumetric method and it could be well quantified by the theoretical considerations in the case that the gas concentration in membrane is higher than the equilibrium concentration defined by the outside pressure. From this quantification, the criteria of the initial set-up conditions for the valid evaluations could be also provided for the volumetric permeability apparatus.

\section{References}

1) T. Nakagawa, S. Yamada : Kagaku Sosetsu, 45, 93 (1984).

2) T. Nakagawa: Maku(Membrane), 6, 197 (1981).

3) D.W. Brubaker, K. Kammermeyer : Ind. Eng. Chem., 44, 1465 (1952).

4) M. Matsuda, C. Kamizawa, K. Haraya, W.T. Lee : Maku (Membrane) 15, (1), 34 (1990).

5) J. Crank : "The Mathematics of Diffusion", 2nd ed., pp. 44-68, Clarendon Press, Oxford (1975).

6) H.A. Daynes : Proc. Roy. Soc. (London), A97, 286 (1920).

7) R.M. Barrer : Trans. Faraday Soc., 35, 628 (1939). 
8) G.J.van Amerongen:Rubber Chem. Technol., 37, 1065 (1964).

9) R. Fielding : Polymer, 21, 140 (1980).

10) S.A.Stern, V.M.Shah, B.J.Hardy : J. Polym. Sci., Polym. Phys. Ed., 25, 1263 (1987).
11) R.M. Barrer, H.T. Chio : J. Polym. Sci., C10, 111 (1965).

12) N. Minoura, S. Tani, T. Nakagawa : J. Appl. Polym. Sci., 22, 833 (1978).

（受付 1989 年 9 月 20 日）

既刊 14 巻 1 号の訂正についてのお願い

14 巻 1 号に所収の下記論文についで, 訂正を要する箇所が発見されました.

P. 50〜P. 53 「ナイロン平膜を用いた回転円筒型フィルタによる血漿分離特性」小笠原啓一・櫛谷文彦・ 酒井清孝

\section{訂正箇所}

P. 51 1) Fig. 2 のグラフがFig. 1 と同一でした.ここに，正しい Fig. 2 を掲載いたします. 2) Fig. 1 の 図説明の下より 2 行目の $\square 4000 \mathrm{rpm}$ ，は $4500 \mathrm{rpm}$ ，之訂正

以上よろしくご訂正お願いいたします。ご迷惑をおかけいたしましたことをお詫びいたします.

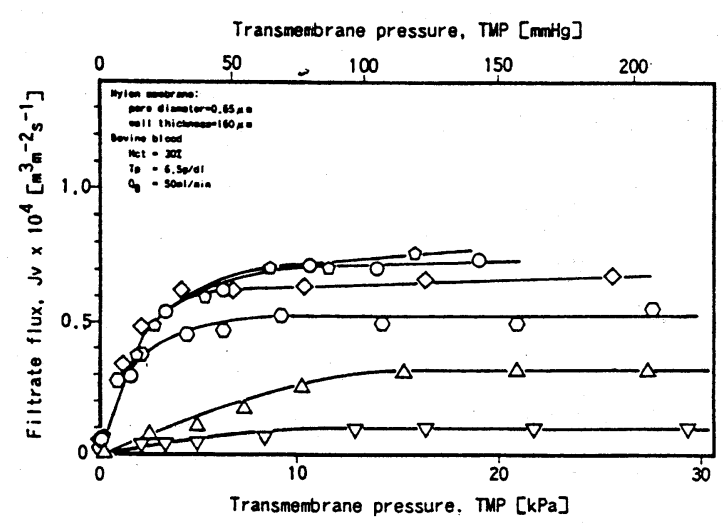

Fig. 1 Filtrate flux for bovine blood with a hematocrit of $30 \%$ and a protein concentration of $6.5 \mathrm{~g} / \mathrm{d} l$ as a function of transmembrane pressure at varying rotational speeds and a blood flow rate of $50 \mathrm{ml} / \mathrm{min}$.

$\triangle 4000 \mathrm{rpm}, \bigcirc 3600 \mathrm{rpm}, \diamond 2500 \mathrm{rpm}$, $\bigcirc 1800 \mathrm{rpm}, \triangle 1200 \mathrm{rpm}, \nabla 600 \mathrm{rpm}$

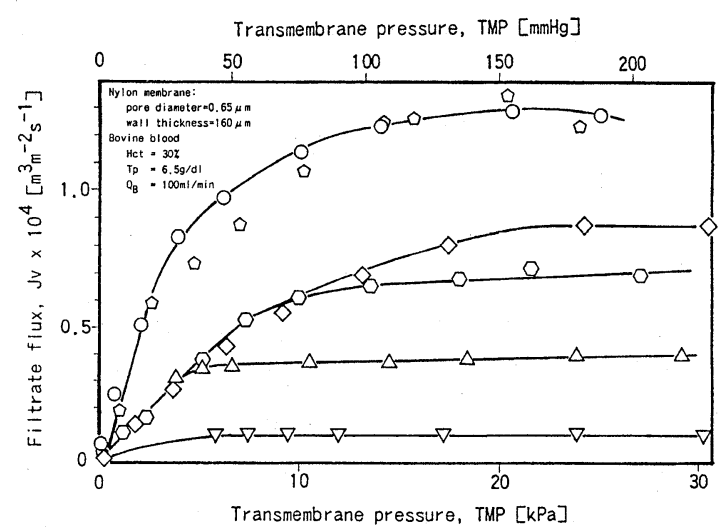

Fig. 2 Filtrate flux for bovine blood with a hematocrit of $30 \%$ and a protein concentration of $6.5 \mathrm{~g} / \mathrm{d} l$ as a function of transmembrane pressure at varying rotational speeds and a blood flow rate of $100 \mathrm{ml} / \mathrm{min}$. 